Britain is a red herring. We agree that we should provide continuity of treatment to drug users from abroad, and we have done so for patients on American maintenance programmes who are taking oral methadone, for example (although these patients' right to care under the NHS is far from clear). But to propose, under the mantle of continuity of treatment, that $80 \mathrm{mg}$ of oral methadone should be changed to $900 \mathrm{mg}$ of injectable heroin (even setting aside the supplementary cocaine at weekends) is surely not within the spirit of continuity of treatment. Furthermore, far from curbing the spread of HIV infection such eccentricities of practice could well provoke a migration of drug users from the United States and elsewhere, with consequent mixing of HIV pools.

Marks's allegation that "London might be a safer and healthier place with fewer addicts" if only we would use "the doses of drugs allowed under the Dangerous Drugs Act" requires robust rebuttal. As Marks must know, there are no dose limits in the legislation: the only controls that prevent Marks or us from prescribing a wheelbarrowful of heroin and cocaine each day are initially peer influence and ultimately a Home Office tribunal.

Those of us who prescribe injectable drugs and other formulations with similarly high potential for misuse and a high resale value on the black market (as in the case we described previously ) are surely obliged (professionally and morally, even if not in law) to make efforts to reduce the misuse of these prescribed drugs.

JOHN STRANG MICHAEL FARRELI

National Addiction Centre,

Maudsley Hospital and Institute of Psychiatry,

London SE5 8AF

1 Marks J. Clinical freedom and drug dependence. $B M F$ 1993;307: 1565. (11 December.)

2 Police lobby for maintenance. Druglink 1992;7(4):4.

3 Marks J. State-rationed drugs. Druglink 1987;2(4):14.

4 Self $W$. Drug dealer by appointment to HM government. Sunday Observer 1992 Sep 13.

5 Strang J, Farrell M. Drug regimens that break a country's drug laws. $B M{ }^{\prime}$ 1993;307:1010. (16 October.)

\section{Adult epiglottitis}

\section{Heightened awareness saves lives}

EDrroR,-M J Stuart and T J Hodgetts draw attention to the fact that epiglottitis is just as life threatening in adults as in children. ${ }^{1} \mathrm{I}$ am aware of two adults who died of epiglottitis in the past seven years. Both presented with severe sore throats but no symptoms of upper airway obstruction until sudden and fatal occlusion of their airways. One had been discharged home and the other was in hospital.

Stuart and Hodgetts also point out that cricothyrotomy may be lifesaving. This is illustrated by a third case. A 20 year old man presented with a sore throat and stridor, which worsened rapidly as he was transferred from the casualty department to the intensive therapy unit. Cricothyrotomy was performed urgently with a Mini-Trach (Portex). His symptoms were rapidly relieved, and oxygenation was improved by passing 6 litres of oxygen/minute down the Mini-Trach tube by an 8 gauge suction catheter. Subsequently he underwent uneventful general anaesthesia and a formal tracheostomy.

Adult epiglottitis is serious but curable. Hopefully, with increased awareness of its presentation and treatment, it will claim fewer lives.

W H KONARZEWSKI

Department of Anaesthetics,

Colchester General Hospital

Colchester CO4 5JL

1 Stuart MJ, Hodgetts TJ. Adult epiglottitis: prompt diagnosis saves lives. $B M f$ 1994;308:329-30. (29 January.)

\section{Causative organism may be elusive}

EDIroR,-M J Stuart and T J Hodgetts recommend that antibiotics effective against Haemophilus influenzae should be given to adults with epiglottitis. ${ }^{1}$ I take issue with this. Although the recommendation is reasonable for the disease in children, which is almost always due to this microorganism, I do not believe that it is sufficient in adult epiglottitis.

I recently helped to manage acute epiglottitis in an adult who required emergency intubation. The patient deteriorated during the first two days of antibiotic treatment with the anti-haemophilus agent cefuroxime, developing both local and systemic complications. The patient had further neck swelling and developed the sepsis syndrome, which was confirmed by haemodynamic measurements with a pulmonary artery balloon flotation catheter; the systemic sepsis resulted in acute renal failure. Because of clinical deterioration benzylpenicillin was added empirically to the antimicrobial regimen. The patient improved over the next few days and was extubated. A group A streptococcus was subsequently cultured from a supraglottic swab and proved sensitive to benzylpenicillin but resistant to cefuroxime. The patient returned home a fortnight later; repeat fibreoptic laryngoscopy showed a normal airway, and renal function recovered spontaneously after conservative fluid management.

Although the organism most commonly identified in acute epiglottitis is $H$ influenzae, positive bacterial cultures have been obtained in at most a third of the cases in all large series of the condition, making recommendations on the likeliest causative organism limited. ${ }^{23}$ In a study by Mayo-Smith et $a l^{4}$ in which a large number of pharyngeal swabs were taken, the commonest pathogen found was group A streptococcus (five of 11 positive cultures), followed by $H$ influenzae (three of 11); the other pathogens were Streptococcus pneumoniae and $H$ parainfluenzae.4 Thus organisms other than $H$ influenzae are important causes of this serious condition, and the case I describe serves as a lesson that giving broader spectrum antibiotic cover in adult epiglottitis is prudent.

University Department of Anaesthesia,

JONATHAN H RAPHAEI Leicester Royal Infirmary, Leicester LE1 5WW

1 Stuart MJ, Hodgetts TJ. Adult epiglottitis: prompt diagnosis saves lives. $B M$ F 1994;308:329-30. (29 January.)

Yenson AC, Zeeb ZE, DeFries HO. Acute epiglottitis in the adult. Laryngoscope 1985;95:289-91.

3 Navarrete ML, Quesada P, Garcia M, Lorente J. Acute epiglottitis in the adult. $₹$ Laryngol Otol 1991;105:839-41.
.

4 Mayo-Smith MF, Hirsch PJ, Wodzinski SF, Schiffman FJ.

Acute epiglottitis in aduts: an eight year experience in Rhode Island. N Engl f Med 1986;314:1133-9.

\section{Establish an airway early}

EDrToR,-Having recently admitted a patient with acute epiglottitis who had had a cardiorespiratory arrest before admission and who later died, we endorse the views of $M J$ Stuart and T J Hodgetts ${ }^{1}$ that epiglottitis may affect people of any age and that the occasionally fatal complication of upper airway obstruction is not restricted to children. ${ }^{2}$ The authors advocate conservative management of the airway in adults in whom respiratory distress is not evident at presentation. We would argue, however, that an elective, "prophylactic" artificial airway should be established at diagnosis in all adult patients (as is routine in paediatric patients) as the risk of airway obstruction is high, there are no reliable early markers of compromise of the airway, and progression to complete closure of the airway may be rapid.

Acute epiglottitis is relatively rare in adults, ${ }^{23}$ and consequently the experience at individual centres is limited. Although estimates vary, one study has shown that the mortality from this condition in adults is similar to that in children before the policy of securing a prophylactic airway in all cases was introduced. ${ }^{2}$ This policy is thought to have reduced the mortality from acute epiglottitis in paediatric patients from $6.1 \%$ to $0.9 \%{ }^{4}$ We believe that as airway obstruction is the main cause of death in acute epiglottitis, irrespective of age, it is logical to advocate the same management for adults as for children. A D HINGORANI J DIERSK
A T JONES D GOLDING-WOOD JM LEIGH

Departments of Medicine, Anaesthesia, and Otolaryngology, Royal Surrey County Hospital, Guildford GU2 5XX

1 Stuart MJ, Hodgetts TJ. Adult epiglottitis: prompt diagnosis saves lives. $B M 7$ 1994;308:329-30. (29 January.)

2 Mayo-Smith MF, Hirsch PJ, Wodzinski SF, Schiffman FJ. Acute epiglottitis in adults: an eight year experience in Rhode Acute epiglottitis in adults: an eight year

3 Trollfors B, Nylen O, Strangert K. Acute epiglottitis in children and adults in Sweden 1981-3. Arch Dis Child 1990;65:491-4.

4 Cantrell RW, Bell RA, Moriaka WT. Acute epiglottitis: intubation versus tracheostomy. Laryngoscope 1978;88:994-1005.

\section{Don't waste time with radiography}

EDrToR,-Partial upper airway obstruction is a common adult emergency presenting to accident and emergency departments. The commonest cause is a reduced level of consciousness. Other causes include foreign bodies, trauma, burns, anaphylaxis, angioneurotic oedema, and tumours. Infections, including epiglottitis, ${ }^{1}$ acute bacterial tracheitis, and acute hypertrophic tonsillitis, may occur. In all of these, life threatening complete airway obstruction may be precipitated quickly and sometimes by minor iatrogenic actions or procedures.

Airway obstruction is a clinical diagnosis, and sometimes a high index of suspicion is needed. I do not recommend radiography of the soft tissue of the lateral neck in the management of patients because the high false negative rate and diagnostic inaccuracy may lead to a false sense of security. The journey to and from the $x$ ray department may precipitate deterioration, and facilities for resuscitation may not be immediately available. Staff experienced in advanced airway management, including anaesthetists and ear, nose, and throat surgeons, should be informed urgently.

Phlebotomy and intravenous access may precipitate acute obstruction of the airway. The patient should be nursed in whatever position he or she finds most comfortable. An oxygen mask may not be tolerated and should not be forced on the patient. A calm and a reassuring approach by all staff is essential to relieve anxiety. Indirect laryngoscopy should be performed only by experienced staff, and facilities for creating a surgical airway should be immediately available if necessary.

Department of Emergency Medicine,

St George's Hospital,

London SW17 0QT

1 Stuart MJ, Hodgetts TJ. Adult epiglottitis: prompt diagnosis saves lives. $B M \mp$ 1994;308:329-30. (29 January.)

\section{Consider underlying malignancy}

EDrroR,-M J Stuart and T J Hodgetts highlight the need to include acute epiglottitis in the differential diagnosis of adults presenting with symptoms of acute pharyngitis with or without respiratory distress.' Fear of missing a case in children is akin to the fear of missing a case of meningitis, and consequently most doctors remain alert to the possibility of the condition. I suspect, however, that epiglottitis is more likely to be missed in adults.

Not only is it critical to diagnose acute epiglottitis early but the possibility of serious underlying 